\title{
How Low Can We Go? The implications of delayed ratcheting and negative emissions technologies on achieving well-below $2^{\circ} \mathrm{C}$
}

\author{
Matthew Winning, Steve Pye, James Glynn, Daniel Scamman and Daniel Welsby
}

\author{
Matthew Winning (corresponding author), UCL Institute for Sustainable Resources, London, UK, \\ m.winning@ucl.ac.uk \\ Steve Pye, UCL Energy Institute, London, UK, s.pye@ucl.ac.uk \\ James Glynn, MaREI Centre, Environmental Research Institute, University College Cork, Cork, Ireland, \\ james.glynn@ucc.ie \\ Daniel Scamman, UCL Energy Institute, London, UK, d.scamman@ucl.ac.uk \\ Daniel Welsby, UCL Institute for Sustainable Resources, London, UK, daniel.welsby.14@ucl.ac.uk
}

\begin{abstract}
Pledges embodied in the nationally determined contributions (NDCs) represent an interim step from a global "no policy" path towards an optimal long-term global mitigation path. However, the goals of the Paris Agreement highlight that current pledges are insufficient. It is, therefore, necessary to ratchet-up parties' future mitigation pledges in the near-term. The ambitious goals of remaining well below $2^{\circ} \mathrm{C}$ and pursuing reductions towards $1.5^{\circ} \mathrm{C}$ mean that any delay in ratcheting-up commitments could be extremely costly or may even make the targets unachievable. In this chapter, we consider the impacts of delaying ratcheting until 2030 on global emissions trajectories towards $2^{\circ} \mathrm{C}$ and $1.5^{\circ} \mathrm{C}$, and the role of offsets via negative emissions technologies (NETs). The analysis suggests that delaying action makes pursuing the $1.5^{\circ} \mathrm{C}$ goal especially difficult without extremely high levels of negative emissions technologies (NETs), such as carbon capture and storage combined with bioenergy (BECCS). Depending on the availability of biomass, other NETs beyond BECCS will be required. Policymakers must also realise that the outlook for fossil fuels are closely linked to the prospects for NETs. If NETs cannot be scaled, the levels of fossil fuels suggested in this analysis are not compatible with the Paris Agreement goals i.e. there are risks of lock-in to a high fossil future. Decision makers must, therefore, comprehend fully the risks of different strategies.
\end{abstract}

Key messages 
- Delaying action will require substantially increased emissions reductions efforts between 2030 and 2050. In particular, achieving targets moving towards $1.5^{\circ} \mathrm{C}$ require immediate action regardless of technology or resource assumptions

- Development of significant levels of biomass are required in all instances as BECCS deployment is essential even for a $2^{\circ} \mathrm{C}$ target

- If policy makers want to achieve targets towards $1.5 \mathrm{oC}$ (or even $2 \mathrm{oC}$ with delayed ratcheting) then consideration of the development of NETs. However, there are risks of lock-in to a high fossil future if NETs fail to scale, the implication of which must be fully understood

- TIMES modelling applied in this chapter allows for the exploration of levels of negative emissions technologies not yet known

\section{Introduction}

The current short-term pledges proposed by countries in the Paris Agreement on Climate Change are an important first step to hold the increase in the global average temperature to well-below $2^{\circ} \mathrm{C}$ above pre-industrial levels and pursuing efforts to limit the temperature increase to $1.5{ }^{\circ} \mathrm{C}$. They are however insufficient to achieve this longterm goal (Hof et al 2017). Increased ambition (or ratcheting as it is referred to in the Paris Agreement) occurring sooner rather than later will be crucial in determining whether the ambitious temperature targets, to stay well below $2{ }^{\circ} \mathrm{C}$ and move towards $1.5^{\circ} \mathrm{C}$ by 2100 , are even possible.

In this chapter, we explore the consequences of a delay until 2030 in the implementation of more ambitious pledges towards the long-term goals of a well-below $2^{\circ} \mathrm{C}$ target and a stricter target towards $1.5^{\circ} \mathrm{C}$. We also assess how much additional effort would be required depending upon when, and if, international effort is increased. A special focus is on global biomass potential given the key role of bioenergy in the feasibility of emission reductions. To undertake the analysis, we utilise the TIAM-UCL model.

The remainder of this chapter is structured as follows. Section 2 describes the TIAMUCL model and the overall assumptions of the study. Section 3 presents the results, with a special focus on the role of negative emissions technologies and prospects for fossil fuels at a global level. Section 4 then provides policy-relevant conclusions and a discussion on what further research is required.

\section{Methods}

\subsection{TIAM-UCL Model}

TIAM-UCL (TIMES Integrated Assessment Model) is a global energy systems model developed at University College London based on the TIMES framework and is developed from an early version of the ETSAP-TIAM model (Loulou and Labriet 2008). 
TIAM-UCL is a partial equilibrium model which uses linear programming and costminimisation to calculate the optimal energy system for a chosen set of energy service demands and technology constraints and is therefore often used for counterfactual policy analysis. The model is technology rich and as such represents all primary energy sources from extraction, through to refinement and conversion, and finally to end-use demand.

The model covers 16 global regions (UK is a separate region) and is calibrated to a base year of 2005, with consideration of the 2010 and 2015 energy balances, using International Energy Agency and UK statistical data with a time-frame which allows model runs out to 2100 in five year time steps. End use energy demands are determined exogenously using regional and sectoral drivers such as GDP, population, households etc. In this analysis, we use the Shared Socioeconomic Pathway (SSP2) projections for GDP and population which drive energy service demands (Riahi et al 2017). Regions in TIAM-UCL are linked by trade in a number of commodities such as hard coal, crude oil, gas via pipelines, LNG, and a variety of petroleum products and energy crops.

A climate module is run in conjunction with TIAM-UCL; it is calibrated to a recent version of MAGICC (Meinshausen et al 2011). In this analysis, we allow net negative emissions of $50 \mathrm{Gt} \mathrm{CO}_{2}$ a year from 2050 onwards. While there is no known limit on negative emissions, in practice there will be some limitations of scaling. Therefore we assume high levels of net negative emissions are possible by allowing for around the same level as current positive emissions are at present. It is unlikely this constraint will ever become binding except in the most extreme of scenarios.

Recent uses of TIAM-UCL include the geographical consideration of unburnable fossil fuels (McGlade and Ekins 2015), fossil trade under climate constraints (Pye et al 2016), and exploring uncertainty in energy modelling (Price and Keppo 2017). Further details of the model are available in the model documentation (Anandarajah et al 2011).

\subsection{Scenarios}

Our scenarios are developed to allow for consideration of the impacts of delayed ratcheting of the NDC commitments, to ascertain how important timing is in achieving the long-term goals. In other words, how low can anthropogenic warming be limited if we delay more ambitious emission reductions and what are the additional changes required in the energy system when ratcheting is delayed?

Conducting further analysis with a "no climate policy" assumption is rather hypothetical since countries have started implementing their plans as proposed in their NDCs. Therefore, our baseline includes the greenhouse gas (GHG) commitments of the NDCs, considering the midpoint between conditional and unconditional commitments. These are for $\mathrm{CO}_{2}, \mathrm{~N}_{2} \mathrm{O}$ and $\mathrm{CH}_{4}$ across all sectors except LULUCF. Other specific commitments, such as renewable energy targets, are not considered. Where emissions reductions are against a hypothetical BAU and the BAU level is not provided, we calculate our own BAU using a regional average from TIAM-UCL. These assumptions 
allow us to have specific GHG targets for all TIAM-UCL regions during the NDC period to 2030 .

Beyond 2030 the assumption in the NDC scenario is to maintain a constant ratio of emissions per GDP/capita. In other words, we consider that emissions do not simply revert to a no-policy case but nor do they keep reducing at the same rate as during the NDC period (Vandyck et al 2016). This can be seen as a vaguely pessimistic assumption in that no further climate policy is implemented beyond the NDCs but that the level of ambition does not decrease below that of the NDC commitments.

Alternative scenarios are defined as follows (Table 1). The "Below $2{ }^{\circ} \mathrm{C}$ " (B2D) and "Towards $1.5^{\circ} \mathrm{C}$ " (T15) scenarios consider the emissions budget over 2015-2100 as proposed by IPCC (2014) and Rogelj et al (2016) for policy analysis. The B2D scenario corresponds to a $66 \%$ chance of reaching $2^{\circ} \mathrm{C}(\mathrm{OECD} / \mathrm{IEA} 2017)$; in other words, this may simply reflect below $2{ }^{\circ} \mathrm{C}$ rather than "well-below". Non- $\mathrm{CO}_{2}$ GHGs are limited to the Representative Concentration Pathway corresponding to RCP2.6 (van Vuuren et al 2011). We also constrain the climate module to upper-temperature limits of $2^{\circ} \mathrm{C}$ and $1.7^{\circ} \mathrm{C}$ in 2100 for the $\mathrm{B} 2 \mathrm{D}$ and $\mathrm{T} 15$ scenarios, respectively. The $\mathrm{CO}_{2}$ and non- $\mathrm{CO}_{2}$ emissions budgets are set separately in the model because TIMES, being an energy systems model, is stronger at analyzing $\mathrm{CO}_{2}$ specifically, than it is at other GHGs. Therefore the addition of a temperature limit ensures the Paris target is met.

Sensitivity analyses are proposed with higher global biomass availability applied to $\mathrm{T} 15$ in order to show the impact that resource availability and resultant technology assumptions can have upon model results and feasibility. The biomass, all of which is considered sustainable, can be used in the system directly or combined with CCS to allow for negative emissions. There are a significant range of estimations for biomass availability in the literature (Resch et al 2008, Cho 2010, Tomabechi 2010). Dornburg et al (2010) estimate that a range of 200-500 EJ is likely once considerations of food security, biodiversity, water availability etc. are internalised and. However, Smith et al (2014) show that there is low agreement on availability being over 100 EJ p.a. Therefore in line with other more conservative assumptions of TIAM-UCL the central biomass availability assumption in our analysis is 150 EJ per year from 2050 onwards; the amount reaches $300 \mathrm{EJ}$ per year in the high availability scenario.

Table 1. Scenario description

\begin{tabular}{ll}
\hline Scenario & Description \\
\hline NDC & $\begin{array}{l}\text { NDC commitments for each region until } 2030 \text { followed by no } \\
\text { further increase in ambition }\end{array}$ \\
B2D & $\begin{array}{l}915 \mathrm{Gt} \mathrm{CO} 2 \mathrm{e} \text { carbon budget }(2015-2100)+\mathrm{RCP} 2.6+2^{\circ} \mathrm{C} \text { temp } \\
\text { limit. Fixed to NDC run until } 2020 . \text { More ambitious reductions } \\
\text { can start from } 2020 .\end{array}$ \\
B2D-2030 & $915 \mathrm{Gt} \mathrm{CO}$ e carbon budget $(2015-2100)+\mathrm{RCP} 2.6+2^{\circ} \mathrm{C}$ temp \\
\hline
\end{tabular}




\begin{tabular}{ll}
\hline & $\begin{array}{l}\text { limit. Fixed to NDC run until 2030. More ambitious reductions } \\
\text { can start from 2030 only. }\end{array}$ \\
\hline B2D-2030-HB & B2D-2030 with increased biomass (From 150 to 300 EJ) \\
& $\begin{array}{l}\text { 400 Gt CO2e carbon budget (2015 - 2100) + RCP 2.6 + 1.7C temp } \\
\text { limit. Fixed to NDC run until 2020. More ambitious reductions } \\
\text { can start from 2020. }\end{array}$ \\
& $\begin{array}{l}\text { 400 Gt CO2e carbon budget (2015 - 2100) + RCP 2.6 + 1.7C temp } \\
\text { limit. Fixed to NDC run until 2030. More ambitious reductions } \\
\text { can start from 2030 only. }\end{array}$ \\
T15-2030-HB & T15-2030 with increased biomass \\
\hline
\end{tabular}

\subsection{Negative Emission Technologies (NETs)}

The development of CCS appears to be crucial in achieving deep long-term emissions reductions. Without CCS, achieving the Paris goals is extremely costly at best and at worst infeasible (Hughes et al 2017). In particular a considerable majority of $2^{\circ} \mathrm{C}$ scenarios runs (104 of 116) in the IPCC AR5 database utilise carbon capture and storage in conjunction with bioenergy (BECCS) as a means of carbon dioxide removal (CDR) (Clarke et al 2014). BECCS results in net negative emissions since residual carbon dioxide emissions is considerably less than the carbon dioxide captured in the biomass growth phase (Smith et al 2016). Many Integrated Assessment Model (IAM) scenarios rely on NETs to cumulatively capture levels of carbon dioxide that are in the same order of magnitude of the remaining $2^{\circ} \mathrm{C}$ carbon budget (Anderson and Peters 2016). However, negative emissions technologies (NETs) are a contentious topic of research (Jackson et al 2017). As a result of a lack of demonstration of these NETs at scale to date, a call for an open discussion for the policy implications of reliance on NETs to achieve temperature stabilisation in IAMs is ongoing (van Vuuren et al 2017). While BECCS is one such NET, other NETs include direct air capture (DAC), enhanced weathering $(\mathrm{EW})$, deep ocean direct injection, subsurface mineralisation, alongside peatland rewetting, biochar, afforestation and reforestation (Tavoni and Socolow 2013).

TIAM-UCL has an upper limit of primary supply of bioenergy of 120-200EJ per year in line with other IAMs (Bauer et al 2017). TIAM-UCL has detailed technology specifications for a range of BECCS across power generation, industry CHP and process heat, as well as upstream biofuels transformation.

Since these do not capture the full spectrum of potential future NETs, and in the absence of a certain set of nascent future NETs, a $\mathrm{CO}_{2}$ backstop technology, which captures $\mathrm{CO}_{2}$ at a high mitigation cost of $\$ 5,000 / \mathrm{tCO}_{2}$ and sequesters $\mathrm{CO}_{2}$ into the available geological storage space in TIAM-UCL, is included in the model to explore marginal mitigation requirements to meet the stringent climate goals. The utilisation of a backstop technology highlights the difficulty in meeting the Paris agreement goals with available mitigation options and suggests that these goals are near the limits of 
technological mitigation within our current understanding of mitigation technologies, expectations of future technological learning, and assumptions of future energy service demands responses to energy prices. The potential further NET options listed, such as DAC and $\mathrm{EW}$, are estimated to be available at marginal abatement costs considerably lower than $\$ 5,000 / \mathrm{tCO}_{2}$ and at mitigation volumes between $3-12 \mathrm{GtCO}_{2} /$ year (Fuss et al 2016) i.e. considerably less than the $\mathrm{CO}_{2}$ backstop technology used in the final period of scenarios in TIAM-UCL. However, research, development and demonstration at scale is required to narrow the range of uncertainty and systemic impacts on electricity and heat requirements, investment and operation costs, land use changes and food competition to appropriately specify more developmental NETs in TIAM-UCL.

\section{Results}

\subsection{The need for negative emissions}

The aggregate global NDC $\mathrm{CO}_{2}$ emissions in 2030 are $40.1 \mathrm{Gt} \mathrm{CO}_{2}$ which represents an increase of $11 \%$ from 2010 levels. For those scenarios that delay ratcheting until 2030, this is the emissions level in 2030 where increased ambition beyond NDCs can begin. Significant emissions reductions are required in all scenarios in order to achieve the long-term Paris goals compared to a NDC baseline beyond 2030 (Fig. 1). Overall net $\mathrm{CO}_{2}$ emissions are around $42 \%$ (39\%) lower in the T15 (B2D) scenario when compared against the NDC run in 2030. During the 2020 to 2030 period, the NDC net emissions increase by $0.2 \%$ a year (as do all the delayed scenarios) whereas B2D and $\mathrm{T} 15$ reduce at $4.6 \%$ and $5.2 \%$ a year, respectively. In particular, there is always a sharp drop in emissions in the period immediately after the policy is tightened i.e. between 2020 and 2025 for the B2D and T15 scenarios and 2030 to 2035 for the other scenarios. It is debatable how realistic these quick drops in global emissions are in practice given lockin of existing capacity but it provides an important insight into how critical near term emission reduction are. 


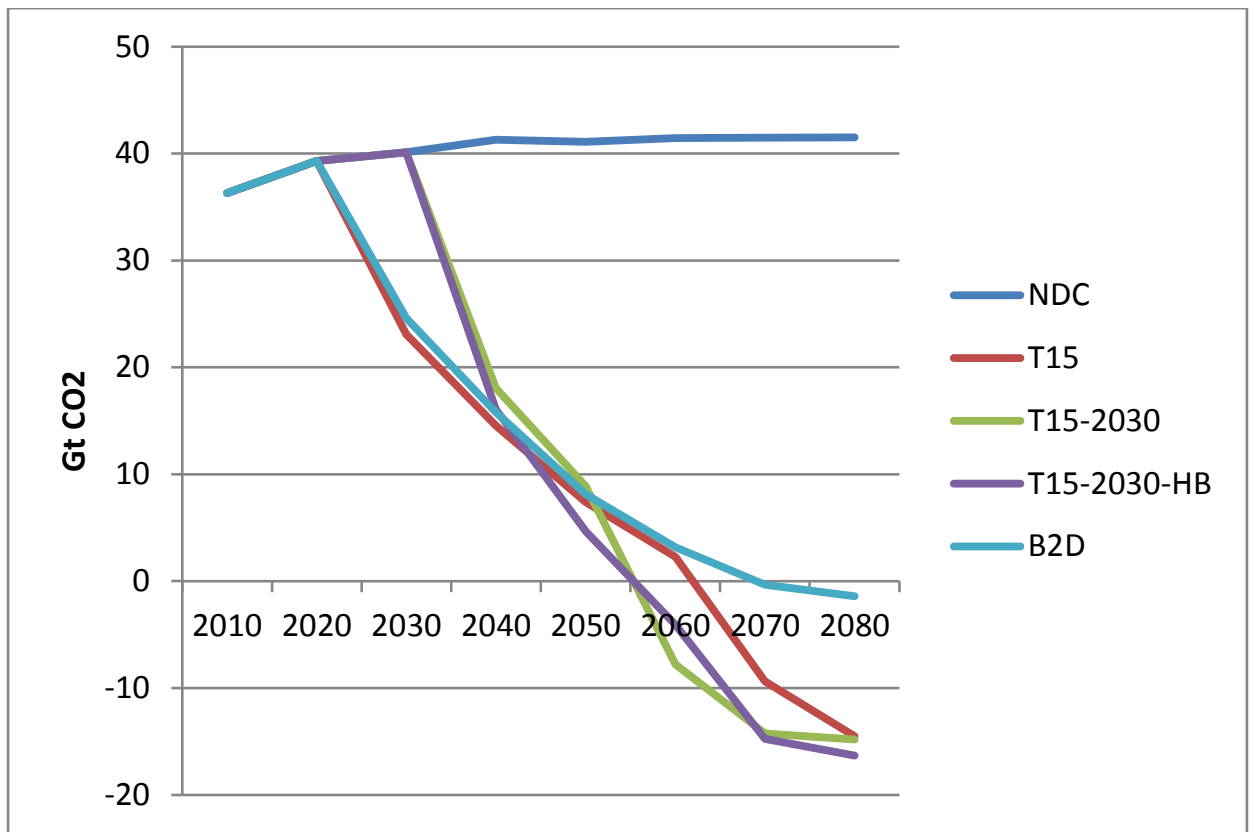

Fig. 1. Global $\mathrm{CO}_{2}$ emissions, 2010-2080 $\left(\mathrm{Gt} \mathrm{CO}_{2}\right)$

In 2030 the majority of emissions savings occur in the electricity sector - electricity $\mathrm{CO} 2$ emissions in the T15 (B2D) scenario are 65\% (64\%) lower than they are in the NDC scenario while transport, industry and buildings sectors are $43 \%(35 \%), 33 \%$ (31\%) and $22 \%$ (21\%) lower, respectively. Furthermore the biggest cut in emissions in moving from B2D to the T15 target occurs in the transport sector showing that, in the near-term, higher and earlier reductions would be needed in the transport sector when attempting to achieve a more stringent long-term emissions goal i.e. going from wellbelow $2^{\circ} \mathrm{C}$ to towards $1.5^{\circ} \mathrm{C}$, and are a cheaper means of achieving global reductions compared to the extra effort in the electricity or other sectors.

In terms of the effort required after 2030, the T15 (B2D) scenario requires yearly net $\mathrm{CO}_{2}$ emissions reductions of around 5.5\% (5.4\%) between the years of 2030 and 2050 whereas an extra 10 years of delayed action mean the yearly reductions in the same period rise to $7.3 \%$ p.a. (6.8\% p.a.). The high biomass scenario T15-2030-HBio (B2D2030-HBio) shows that deeper emissions reductions are possible between 2030 and 2050 as $\mathrm{CO}_{2}$ reductions in the region of $10.2 \%(6.8 \%)$ per year are possible due to greater the ability to employ larger amounts of biomass and BECCS throughout the model run.

All B2D and T15 emissions reduction scenarios have net $\mathrm{CO}_{2}$ emissions in 2050 lower than $10 \mathrm{Gt} \mathrm{CO}_{2}$. Indeed, net emissions become negative between 2060 and 2070 in all scenarios, which is consistent with the Paris Agreement's goal of "achieving net zero emissions by the second half of this century," unlike the NDC baseline. Net negative 
emissions are then achieved by 2060 for T15-2030 and T15-2030-HB, where the most stringent emissions reductions are required in the shortest time-frame. Cumulatively, these net negative emissions over the time horizon amount to $437 \mathrm{Gt}$ for $\mathrm{T} 15$ and around $580 \mathrm{Gt}$ in both the delayed $1.5^{\circ} \mathrm{C}$ scenarios. In all the well-below $2^{\circ} \mathrm{C}$ scenarios there are low levels of net negative emissions which occur from 2070 and beyond with only 17 cumulative $\mathrm{Gt}^{\mathrm{CO}_{2}}$ below zero in the B2D instance and around $230 \mathrm{Gt}$ in the other two $2^{\circ} \mathrm{C}$ delayed scenarios. The technologies which allow for net negative emissions are discussed further in section 3.2

\subsection{CCS, BECCS and other NETs}

By the middle of the century, both fossil CCS and BECCS will play a crucial role in decarbonisation efforts regardless of stringency of emissions reductions (Fig. 2). In $2050, \mathrm{CO}_{2}$ capture in electricity and upstream sectors become important in all reduction scenarios, capturing around $50 \%$ of these sectors' emissions, while around a fifth of industry $\mathrm{CO}_{2}$ emissions are captured. Importantly, as a negative emissions technology, BECCS not only sequesters carbon emissions from bio-energy when it is combusted but gains negative credit based on the assumption that the combusted emissions would have been sequestered in the biosphere, in trees/plants etc. (Smith et al 2015). All of the nonNDC scenarios utilize BECCS in 2050 to the order of 6 to $8 \mathrm{Gt} \mathrm{CO}_{2}$. However, there are significant uncertainties in the availability and scaling of these technologies which suggests that performing a sensitivity analysis around them is crucial to model results (Anderson \& Peters 2016). 


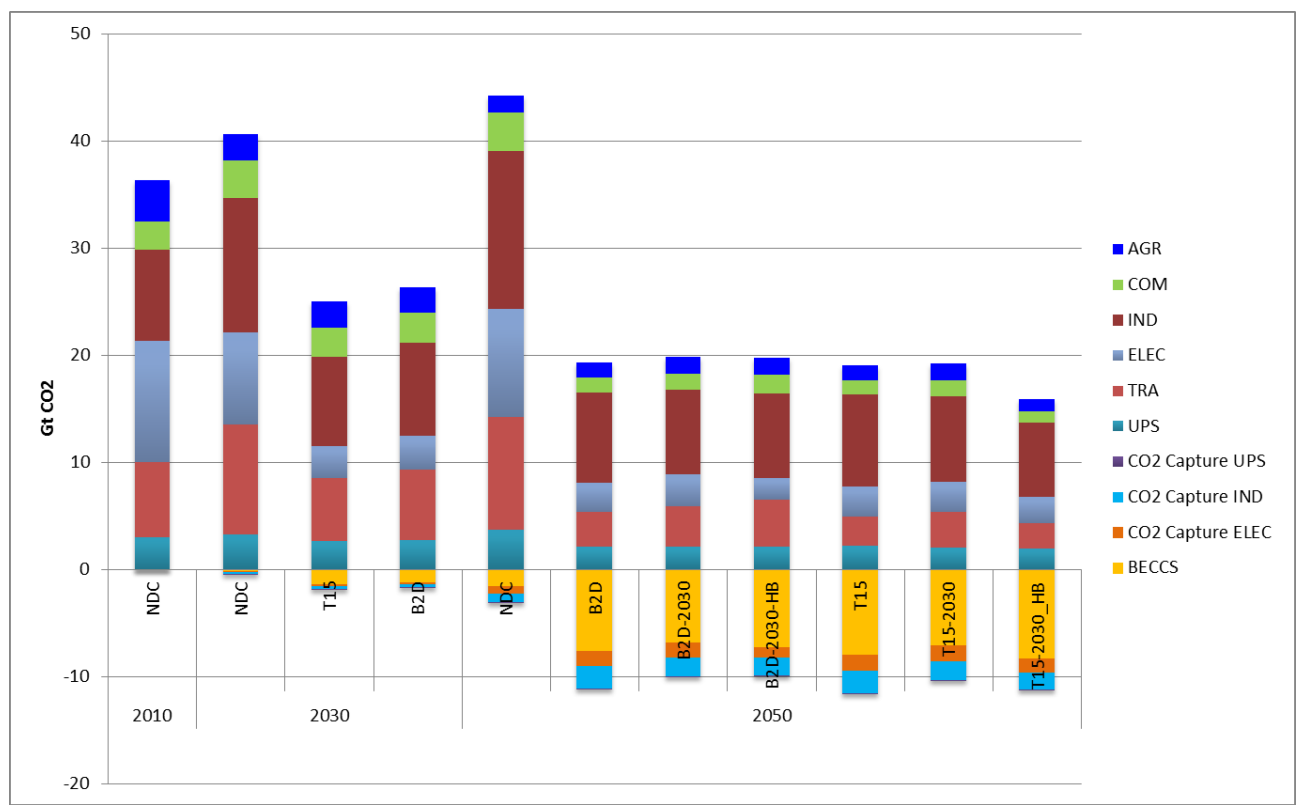

Fig. 2. CO2 emissions by sector in 2030 and 2050 (Mt CO2)

An important finding is that NETs, not yet specified, at a high marginal abatement cost (\$5000 per tCO2), are being utilised in all scenarios except NDC and B2D-2030HB (Table 2). These NETs are deployed as a last resort given its extremely high cost, and reflects the absence of any known alternative mitigation opportunity in the model or possibly the fact that known technologies cannot be deployed at a sufficiently high rate due to constraints imposed.

Table 2. Cumulative emissions from BECCS and other NETs compared against carbon budget

\begin{tabular}{lccccccc}
\hline Scenario & $\begin{array}{c}\text { Carbon } \\
\text { Budget } \\
\text { (Gt CO2) } \\
\mathbf{2 0 1 5 - 2 1 0 0}\end{array}$ & $\begin{array}{c}\text { BECCS } \\
\text { (Gt CO2) }\end{array}$ & $\begin{array}{c}\text { \%15-2100 } \\
\text { vs Carbon } \\
\text { Budget }\end{array}$ & $\begin{array}{c}\text { Other } \\
\text { NETs } \\
\text { (Gt CO2) }\end{array}$ & $\begin{array}{c}\text { \% Other } \\
\text { NETs vs } \\
\text { carbon } \\
\text { budget }\end{array}$ & $\begin{array}{c}\text { Total } \\
\text { NETs } \\
\text { (Gt CO2) }\end{array}$ & $\begin{array}{c}\text { \% Total } \\
\text { vs carbon } \\
\text { budget }\end{array}$ \\
\hline T15 & 400 & 543 & $136 \%$ & 415 & $104 \%$ & 958 & $213 \%$ \\
\hline $\begin{array}{l}\text { T15-2030- } \\
\text { HB }\end{array}$ & 400 & 792 & $198 \%$ & 279 & $70 \%$ & 1072 & $238 \%$ \\
T15-2030 & 400 & 496 & $124 \%$ & 674 & $168 \%$ & 1170 & $260 \%$ \\
\hline B2D & 915 & 531 & $58 \%$ & 11 & $1 \%$ & 541 & $60 \%$ \\
\hline $\begin{array}{l}\text { B2D-2030- } \\
\text { HB }\end{array}$ & 915 & 784 & $86 \%$ & 0 & $0 \%$ & 784 & $87 \%$ \\
\hline B2D-2030 & 915 & 509 & $56 \%$ & 257 & $28 \%$ & 766 & $85 \%$ \\
\hline
\end{tabular}




\begin{tabular}{llllllll}
\hline NDC & N/A & 134 & N/A & 0 & - & 134 & N/A \\
\hline
\end{tabular}

For the $2^{\circ} \mathrm{C}$ scenarios, other NETs are not needed when biomass availability assumptions are higher than our standard assumption. In fact it appears the $150 \mathrm{EJ}$ p.a. biomass availability assumption is for the point at which BECCS is the only negative emissions technology required i.e. if assumption is any lower than around $150 \mathrm{EJ}$ then Other NETs are required in the system. This finding is apparent as there is only around $10 \mathrm{Gt}$ of cumulative $\mathrm{CO}_{2}$ emissions captured by Other NETs in B2D, which for context is about $1 \%$ of the total $\mathrm{B} 2 \mathrm{D}$ carbon budget, and therefore a small increase in the biomass assumption would remove the need for any Other NETs. In fact, there are no Other NETs required in the B2D-2030-HB scenario at all, against $257 \mathrm{Gt} \mathrm{CO} 2$ required in the lower biomass scenario to achieve the target. These results show the importance of sensitivity analysis around biomass availability in modelling. For policymakers it reflects the criticality of communicating such results so these issues are not hidden, and the necessary efforts required on NETs research and future planning for adequate bioenergy resources.

The results indicate that moving to well below $2^{\circ} \mathrm{C}$ is achievable with either no or low levels of Other NETs as long as there is no delay in ratcheting. When biomass availability is higher, some delay is even possible. However, substantial amounts of Other NETs are required in all the scenarios which are aiming towards $1.5^{\circ} \mathrm{C}$. In 2070 they are required for the T15 scenario and even earlier - 2055 and 2060 - for the T152030 and T15-2030-HB scenarios, respectively.

In the T15 scenario, the 'Other NETs' technology is used to mitigate some $415 \mathrm{Gt}$ $\mathrm{CO}_{2}$ towards the end of the time horizon. This means that the whole of the budget under the T15 scenario relies on a yet-to-be specified mitigation technology. T15-2030-HB has a lower yet still significant amount of Other NETs emissions at $279 \mathrm{GtCO}_{2}$. However, the T15-2030 has considerably larger deployment as 674 Gt CO2 between 2055 and 2100. These can be seen as the amount of emissions that would have to be reduced elsewhere in the energy system in order to meet the stipulated emissions target. It must be stressed that considerable amounts of investment in R\&D will be required to ensure these NETs become available in the short-term and in order to reduce costs, or will need to see much more rapid action in the near term on fossil fuel phase out. Therefore if policymakers are serious about moving towards $1.5^{\circ} \mathrm{C}$ then action must occur without delay in order to make sure technologies are available and for costs to be reasonable.

\subsection{Some fossil fuels survive due to CCS and NETs}

Given the emissions outlook presented above, and the role of NETs, it is insightful to explore the use of fossil fuels in future years. What is clear is that their continued use is permitted due to the availability of CCS, and the offsets provided by negative emissions generated by BECCS. This is an important issue to remember when interpreting the 
results below. For example, B2D has a carbon budget of $915 \mathrm{GtCO}_{2}$, which is increased by $60 \%$ through NETs; without NETs, emissions from fossil fuels would need to be $60 \%$ lower, in other words, not consumed. Table 3 below shows the reductions in consumption for coal, oil and natural gas, relative to the NDC baseline..

\subsubsection{Coal}

Due to its high carbon intensity, coal sees the largest reductions of all fuels across all scenarios, relative to the NDC baseline. In the NDC baseline global coal consumption remains relatively stable around $150 \mathrm{EJ}$ until 2035 , before increasing linearly to around $250 \mathrm{EJ}$ by 2080 ; regionally this is due to a phase out of coal in the developed economies of Western Europe, the UK, Canada, and the US, whilst allowing India and China more time to transition (i.e. consumption in India and China offsets the reductions made by the developed economies).

When the NDC commitments move to below $2^{\circ} \mathrm{C}$ or towards $1.5^{\circ} \mathrm{C}$, huge reductions in coal consumption are required, particularly in India and China, where unprecedented phasing out of coal is required to meet carbon reduction targets. In other words, coal does not survive even with CCS and NETs available in the scenarios.

Of particular interest in India is the implication of delaying the ratcheting up of their NDC commitments to 2030, with coal consumption increasing between 2020-2030, and thus requiring an even greater reduction from 2030 (in both of the B2D-2030 and T152030 scenarios); in India as in other developing regions, the flexibility of the energy system, and in particular power generation, to adapt to this is absolutely fundamental, and the policy implications of this study encourages action now in order to facilitate consumption 'smoothing', as coal is phased out (i.e. to avoid a shock reduction in demand in 2030).

The importance of a global effort to substantially reduce coal as soon as possible can be seen in the B2D and T15 scenarios where the energy system turns rapidly towards electrification; in the first ten years after more stringent carbon reduction targets are introduced above the NDC baseline, delaying action to 2030 requires the installation of around $30 \%$ more generation capacity in all B2D and T15 scenarios, when compared to electricity capacity investments when carbon budgets are ratcheted up in 2020 . India and China account for between $56-67 \%$ of total remaining global coal consumption by 2050 in the B2D and T15 scenarios, predominantly as an input to the industrial and electricity generation sectors. Additionally, by 2050 , at least $70 \%$ of electricity generation from coal relies on CCS capabilities (for reference, across the B2D and T15 scenarios electricity generation from coal accounts for less than $2 \%$ of total electricity generation).

Table 3. Percentage change in global fossil fuel consumption for each scenario relative to the NDC baseline

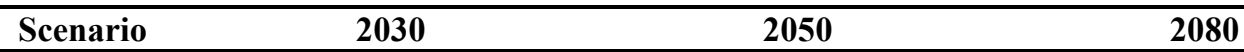




\begin{tabular}{lccccccccc}
\hline & Coal & Oil & Gas & Coal & Oil & Gas & Coal & Oil & Gas \\
B2D & $-69 \%$ & $-17 \%$ & $-12 \%$ & $-83 \%$ & $-44 \%$ & $-33 \%$ & $-78 \%$ & $-56 \%$ & $-33 \%$ \\
\hline B2D-2030 & - & - & - & $-82 \%$ & $-41 \%$ & $-42 \%$ & $-73 \%$ & $-59 \%$ & $-42 \%$ \\
\hline B2D-2030-HB & - & - & - & $-79 \%$ & $-36 \%$ & $-30 \%$ & $-75 \%$ & $-53 \%$ & $-30 \%$ \\
T15 & $-73 \%$ & $-29 \%$ & $-19 \%$ & $-84 \%$ & $-47 \%$ & $-41 \%$ & $-81 \%$ & $-59 \%$ & $-52 \%$ \\
\hline T15-2030 & - & - & - & $-81 \%$ & $-46 \%$ & $-44 \%$ & $-74 \%$ & $-56 \%$ & $-44 \%$ \\
\hline T15-2030-HB & - & - & - & $-85 \%$ & $-55 \%$ & $-55 \%$ & $-87 \%$ & $-60 \%$ & $-68 \%$ \\
\hline
\end{tabular}

Reminder: In B2D-2030 and T15-2030 scenarios, the results are fixed to the NDC baseline until 2030 so there is no difference in consumption up to 2030

\subsubsection{Gas}

The highest level of gas consumption, when aggregated globally, is in the NDC baseline scenario, reaching just over 200 EJ by 2050 . In short, the more stringent carbon budgets imposed in the B2D and T15 scenarios means that global gas consumption is consistently below the NDC baseline across the entire modelling time horizon. However, the relative reduction in global gas consumption below the NDC baseline is far less than the reductions required for coal consumption. Additionally, delaying action to 2030 requires more rapid reductions in natural gas consumption across all of the $\mathrm{B} 2 \mathrm{D}$ and $\mathrm{T} 15$ scenarios.

Globally, natural gas consumption in the electricity generation sector remains relatively stable across all the $\mathrm{B} 2 \mathrm{D}$ and $\mathrm{T} 15$ scenarios with medium biomass availability until 2045, relying on CCS for around $40 \%$ of this generation, before declining sharply from 2045-50. Of particular interest for natural gas consumption in the power generation sector is the impact of higher biomass availability; in both the B2D-2030 and T15-2030 scenarios with high biomass availability, electricity generation from natural gas falls rapidly from 2030 , before stabilizing from 2060 . Additionally gas consumption in the residential sector reduces as energy service demand (e.g. residential heating, cooling, and cooking) is increasingly satisfied by electricity.

The industrial sector (chemicals, iron and steel, paper and pulp, non-ferrous metal production, etc.) maintains a relatively steady level of gas consumption in all the B2D and T15 scenarios (between 50-65 EJ out to 2080). Focusing on the industrial sector, three key issues are as follows:

Firstly, the relatively stable level of gross natural gas consumption in the industrial sector is predominantly due to consistently large, and relatively stable, consumption by the chemical and petrochemical sub-sectors.

Secondly, global consumption of natural gas in heavy industries (i.e. iron and steel production) is higher in the B2D and T15 scenarios than in the NDC baseline for all years post-2030, and experiences growth in all three T15 scenarios until 2045, as coking coal/other coal (generally lower energy content) inputs into the production process are replaced in favor of natural gas.

Thirdly, the regional variation in industrial natural gas consumption demand depends to a large extent on future economic restructuring and exogenous drivers, which will 
have significant implications for global natural gas trading patterns and individual regions/countries emissions profiles (i.e. where will heavy industry and chemical/petrochemical production be situated).

\subsubsection{Oil and the transport sector}

In 2015, the transportation sector accounted for around 64\% of global oil consumption (IEA 2017). As decarbonisation policies are ratcheted up, oil is more rapidly substituted in the transportation sector by natural gas, hydrogen, and electricity. However significant uncertainties surround this transition, particularly for hydrogen and electric vehicles, which require large infrastructural investments including for production, distribution and refueling (Morton et. al 2014, Scamman 2017). In all of the B2D and T15 scenarios, oil consumption in the transportation sector is significantly reduced by 2050 to between 30-45 EJ against $120 \mathrm{EJ}$ in the NDC scenario.This requires a reduction of between $75-80 \%$ from 2015 levels. Oil consumption is highly sensitive to how quickly carbon budgets are ratcheted in ambition, as well as the availability of biomass in the T15 case (oil consumption is $10 \mathrm{EJ}$ higher in the T15-2030 scenario in 2050, compared to the T15-2030 scenario with high biomass availability).

Transportation energy service demand in all of the B2D and T15 scenarios is below the NDC baseline, with an increased shift to pooling/public transportation modes, as well as efficiency improvements across the vehicle fleet. From an energy input vector perspective, natural gas, and in particularly liquefied natural gas combustion engines are utilized far less in the T15 scenarios, when compared to the B2D cases. Part of this natural gas is replaced by hydrogen, including fuel cell technologies, which become increasingly prevalent in the T15 scenarios, representing between $28-36 \%$ of transport sector energy consumption by 2050 . Across all scenarios, electricity maintains a relatively stable level of gross input to satisfy transport energy demand by 2050, with between 15-20 EJ. It should be noted that much of the above analysis depends on the direction of policy support, which can assign 'winners' and 'losers' before the diffusion of a technology.

The insights above are therefore heavily dependent on the level of policy support, the level at which the externalities (i.e. emissions) of existing vehicles are taxed, and the availability and cost of different technologies across regions, including the required feedstock fuels.

\section{Conclusion}

This chapter uses the TIAM-UCL model to consider the effects on the global energy system of delaying the ratcheting of the NDCs when attempting to achieve the long-term goals of below $2^{\circ} \mathrm{C}$ and towards $1.5^{\circ} \mathrm{C}$.

Ratcheting-up commitments now becomes critical to go beyond $2^{\circ} \mathrm{C}$ towards $1.5^{\circ} \mathrm{C}$. The rate of emissions reductions required when effort is delayed to 2030 is significantly higher as well as the reliance on large-scale NETs deployment, despite its high cost. 
Delaying also requires larger levels of bioenergy resource to have any chance of meeting the target, due to its use in combination with CCS (BECCS) to generate negative emissions.

An availability of slightly above $150 \mathrm{EJ}$ per year allows for the $2^{\circ} \mathrm{C}$ target without delay to be met using BECCS but without any other NETs required. The delayed scenarios are highly sensitive to the availability of biomass. The $2^{\circ} \mathrm{C}$ target with a high biomass assumption also does not require any other NETs beyond BECCS. However, when biomass is at its medium availability with delay then around $257 \mathrm{Gt} \mathrm{CO}_{2}$ of NETs are required cumulatively, which is employed in combination with BECCS deployment meaning BECCS and NETs combined amount to $84 \%$ of the total carbon budget. This reliance on biomass availability implies significant policy implications, not least due to uncertainties over land-use and land-use changes.

Delay increases the reliance not only on BECCS but on other NETs that are not yet well known. Without those NETs, the $1.5^{\circ} \mathrm{C}$ target appears to be unachievable. It is critical that the levels of negative emissions are revealed to the policy community so that they are clear as to what their current strategies are premised on. It is also critical, as we have done in this analysis, to reveal that for some levels of ambition our models do not solve for the most ambitious targets, unless we introduce proxy NETs options.

If large scale amounts of negative emissions are to be avoided in moving towards $1.5^{\circ} \mathrm{C}$, efforts must focus on those sectors where residual emissions occur in the later periods, such as industry and electricity, whose positive emissions require offsetting via negative emissions. Clearly technological innovation or demand reduction in these sectors should be a priority for those who do not believe that BECCS and NETs can be deployed at such a scale.

However, it is inevitable that some level of CCS/NETs will be required in the future. This is the case for two reasons; i) both levels of ambition see emissions going netnegative, due to a large part of the budget being used prior to 2050, and ii) some sectors will be extremely challenging to decarbonize. Therefore, policy makers need to start orientating the agenda and action towards such technologies whose commercial development is still uncertain.

It is also important that decision makers understand that the prospects for fossil fuels are very much tied to the outlook for NETs. If NETs cannot be scaled, the levels of fossil fuels suggested in this analysis are not compatible with the Paris Agreement goals. In other words, there are risks of lock-in to a high fossil future if NETs fail to scale. Policy makers must therefore understand well the risks of different strategies. To reduce the risks of lock-in to a high fossil future, policy makers may be interested in exploring pathways with lower levels of CCS/NETs, to help develop strategies that are more robust to the risks of failure.

To help inform the debate, it is also critical that greater attention is paid to the demand side of the model to balance the focus away from 'supply-side only' solutions. This means a focus on the underlying drivers, non-technical measures focused on societal behavior, and the changing delivery of energy services e.g. mobility as a service 
(MaaS) in the transport sector, and measures to reduce industrial emission intensity e.g. changes to materials used in the economy (circular economy etc.). Recognising the uncertainty, particularly in the case of economic drivers, which tend to project current economic forecasts and structures forward in time, is crucial given the tendency for significant changes in economic regimes, both nationally and globally. In TIAM-UCL, the projections suggest continuous economic growth driving income levels and demand for energy services e.g. air travel. However, other futures are very much possible and should be explored.

\section{References}

Anderson K, Peters G (2016) The trouble with negative emissions. Science 354(6309): 182-183. doi: 10.1126/science.aah4567

Bauer N et al (2017) Shared Socio-Economic Pathways of the Energy Sector - Quantifying the Narratives. Global Environmental Change 42: 316-330.

Cho A (2010) Energy' s Tricky Tradeoffs. Science 786-7. doi:10.1126/science.329.5993.786

Clarke L et al (2014) Mitigation of Climate Change. In: Edenhofer et al (eds) Climate Change, Ch. 6. Cambridge Univ.Press.

Criqui P, Mathy S (2016) The pragmatic approach of the Paris Agreement: The role of INDCs and deep decarbonization pathways. Economics and Policy of energy and the environment. 3/2016: 79-87. doi:10.3280/EFE2016-003007

Dornburg V, van Vuuren DP et al (2010) Bioenergy revisited: Key factors in global potentials of bioenergy. Energy \& Environmental Science. doi: 10.1039/b922422j

Fuss S et al (2016) Research priorities for negative emissions. Environmental Research Letters 11(11). doi: $10.1088 / 1748-9326 / 11 / 11 / 115007$

Geden O (2015) Climate advisers must maintain integrity. Nature 521:27-28. doi: 10.1038/521027a

Global CCS Institute (2010) Global Status of BECCS Projects 2010. http://hub.globalccsinstitute.com/sites/default/files/publications/13516/gccsi-biorecro-global-statusbeccs-110302-report.pdf. Accessed 12 Jan 2018

Hof AF et al (2017) Global and regional abatement costs of Nationally Determined Contributions (NDCs) and of enhanced action to levels well below $2{ }^{\circ} \mathrm{C}$ and $1.5^{\circ} \mathrm{C}$. Environmental Science and Policy 71(1): 30-40. http://doi.org/10.1016/j.envsci.2017.02.008

Hughes et al (2017) The role of CCS in meeting climate policy targets: understanding the potential contribution of CCS to a low carbon world, and the policies that may support that contribution. http://www.globalccsinstitute.com/publications/report-university-college-london-role-ccs-meetingclimate-policy-targets. Accessed 12 Jan 2018

IEA (2017) Key World Energy Statistics. https://www.iea.org/publications/freepublications/publication/KeyWorld2017.pdf. Accessed 12 Jan 2018 
IPCC, 2014: Climate Change 2014: Synthesis Report. Contribution of Working Groups I, II and III to the Fifth Assessment Report of the Intergovernmental Panel on Climate Change [Core Writing Team, R.K. Pachauri and L.A. Meyer (eds.)]. IPCC, Geneva, Switzerland, 151

Jackson RB et al (2017) Focus on negative emissions. Environmental Research Letters 12. doi: 10.1088/1748-9326/aa94ff

Loulou R, Labriet M (2007) ETSAP-TIAM - the TIMES integrated assessment model Part 1: Model structure. CMS 5: 7-40. doi: 10.1007/s10287-007-0046-Z

McGlade C, Ekins P (2015) The Geographical distribution of fossil fuels unused when limiting global warming to $2^{\circ} \mathrm{C}$. Nature 517: 187 - 190. doi: 10.1038/nature14016

Meinshausen M, Raper SCB, Wigley TML (2011) Emulating coupled atmosphere-ocean and carbon cycle models with a simpler model, MAGICC6 - Part 1: Model description and calibration. Atmospheric Chemistry and Physics 11(4): 1417-1456. doi: 10.5194/acp-11-1417-2011

Morton C, Anable J, Brand C (2014) UKERC Energy Strategy Uncertainties. Perceived Uncertianty in the Demand for Electric Vehicles: A Qualitative Assessment. http://www.ukerc.ac.uk/publications/ukerc-energy-strategy-under-uncertainties-perceiveduncertainty-in-the-demand-for-electric-vehicles-a-qualitative-assessment.html. Accessed 12 Jan 2018

Peters GP, Geden O. (2017) Catalysing a political shift from low to negative carbon. Nature Climate Change 7: 619-621. doi:10.1038/nclimate3369

Pye S et al (2016) Exploring national decarbonization pathways and global energy trade flows: a multiscale analysis. Climate Policy 16(1): 92-109. doi: 10.1080/14693062.2016.1179619

Resch G, Held A, Faber T, Panzer C, Toro F, Haas R, (2008) Potentials and prospects for renewable energies at global scale. Energy Policy 36: 4048-4056. doi:10.1016/j.enpol.2008.06.029

Riahi K et al (2017) The Shared Socioeconomic Pathways and their energy, land use, and greenhouse gas emissions implications: An overview. Global Environmental Change 42: 153-168. doi: 10.1016/j.gloenvcha.2016.05.009

Rogelj MS (2016). Differences between carbon budget estimates unravelled. Nature Climate

Change 6: 245-252. doi: $10.1038 /$ nclimate2868

Scamman D (2017) The Transport Sector. In: Staffell I, Dodds PE (Eds.) The role of hydrogen and fuel cells in future energy systems. H2FC SUPERGEN, London, p 53-70

Smith P et al (2014) Agriculture, Forestry and Other Land Use (AFOLU). In: Climate Change 2014: Mitigation of Climate Change. Contribution of Working Group III to the Fifth Assessment Report of the Intergovernmental Panel on Climate Change [Edenhofer OR, et al (eds.)]. Cambridge University Press, Cambridge, United Kingdom and New York.

Smith P et al (2016) Biophysical and economic limits to negative CO2 emissions. Nature Climate Change 6: 42-50. doi: 10.1038/nclimate2870

Tavoni M, Socolow R (2013) Modeling meets science and technology: an introduction to a special issue on negative emissions. Climatic Change 118:1-14. doi 10.1007/s10584-013-0757-9

Tomabechi K. (2010) Energy resources in the future. Energies 3: 686-695. doi:10.3390/en3040686

van Vuuren DP et al (2011) The representative concentration pathways: An overview. Climatic Change 109(1): 5-31. doi: 10.1007/s10584-011-0148-Z 
van Vuuren DP et al (2017) Open discussion of negative emissions is urgently needed. Nature Energy 2: 902904. doi: 10.1038/s41560-017-0055-2 